\title{
Research on Control of the Clean Governance Risk in University Project Bidding*
}

\author{
Shuli Li \\ China West Normal University \\ Nanchong, China
}

\author{
Lijun Luo \\ China West Normal University \\ Nanchong, China
}

\begin{abstract}
Through researching on the university project bidding, this paper defines the control of clean governance risk in university project bidding, and identifies three types of risks in respect of the situation in university: bidding environment risk, bidding management mechanism risk, bidding quality risk, and analyzes the causes. It introduces to strengthen the clean governance mechanism inside universities, upgrade the management mechanism of the university project bidding, enhance its quality control system, and improve business ability of the staff to cope with the clean governance risk in the university project bidding.
\end{abstract}

Keywords-university; project bidding; clean governance risk; control

\section{INTRODUCTION}

As the state provides further support for investment in the development of universities, the development of universities is booming, but cases of severe violations of law and discipline in universities have also been came to light consistently, especially the cases of corruption in university project bidding. The clean governance risk in the project bidding directly affects the fairness, impartiality and openness of the bidding. The higher risk of clean governance is with the constant changes in the project bidding environment. Some control measures shall be taken for risk points of clean governance so that we can adapt to new circumstances, in a bid to cleanse the university project tender environment and strengthen university administration.

\section{CONTROL OF CLEAN GOVERNANCE RISK IN UNIVERSITY PROJECT BIDDING}

Clean governance risk in university project bidding is the possibility what the bidding officer or relevant personnel have to take legal responsibility due to violate the law of integrity during the bidding. The more open and fair the bidding is, the better quality and the lower clean governance risk will be in the bidding. Searching in the referenced documents, it is found that our theoretical and practical workers have been exploring and taking effective measures to control the clean governance risk in universities since the early 21 st century, such as

*This paper is supported by the fundamental research funds of China West Normal University

Project title: Research on the construction of control of clean governance risk in university project bidding, project number: $17 \mathrm{G} 011$. developing a clean campus culture, strengthening control of key areas, putting forward the system, and implementing the responsibility system. Through studying on the university project bidding, we identify, analyze and control its clean governance risk, in a bid to further the theoretical research on the clean governance in university.

Effective control of clean governance risk in university project bidding helps to develop clean governance in universities which is of great significance to accomplishment of the project bidding. It helps the relevant departments of the university to take measures proactively to reduce risks in some key points. The risk control in university project bidding is a systematic project, of which each stage and each link, from the preparation of bidding plan and bidding control price to the announcement of bidding, acceptance of registration, qualification examination, sale of bidding documents, bidding and answering questions to bid opening, bid evaluation, publicity, issuing bidding notice, etc. , need to be strengthened; any errors or violations caused by failure in risk management will affect the entire bidding.

\section{IDENTIFICATION AND ANALYSIS OF CLEAN} GOVERNANCE RISK IN UNIVERSITY PROJECT BIDDING

The clean governance risk has many factors, including external factors, and factors inside the university and factors from the bidding staff, which directly or indirectly affect the project bidding. Based on the university project bidding, there are three major risks: bidding environmental risks, bidding management mechanism risks, and bidding quality risks. The causes and performance of the risks are as follows:

\section{A. Environmental Risks}

University project bidding is an open and procedural activity for the whole society. The bidding work has two kinds of environmental risks in a dynamic social environment:

1) External environmental risk: For the purpose of benefiting their own interests, the bidder or others with interests may seduce or abnormal influence the bidding staff or the relevant consulting institutions or professionals entrusted by the university, so that there are clean governance risks with serious consequences including dereliction of duty or power-for-money deals cause by disciplinary violations of personnel involved in project bidding in universities. The 
emergence of external environmental risks is because of the open university project bidding activities. The diversified forms of corruption, the random corruption and the variability of personnel in corruption practices, raise the risk of the external environment. Compared with environment inside the universities, the external environment is more complicated and more uncontrollable.

2) Internal environmental risk: Due to inadequate control mechanism of clean governance risk in university and lack of the atmosphere and culture of clean governance, the bidding staff have sick and the prevention of corruption. Compared with the external environment, the bidding staff not only participates in building university's clean governance and its culture, but also are the educatee. A good-and-bad internal environment will directly affect awareness of the bidding staff in clean governance to resist corruption.

\section{B. Project Bidding Management Mechanism Risk}

The clean governance system should be closely integrated with the project bidding management system, without it building clean governance rules will cause separate rules. The project bidding management mechanism means a process and method to complete the project bidding work through the interaction between the organization and department of the university project bidding system. It has two types of project bidding management mechanism risk:

1) Risk of inadequate system: All relevant personnel shall be compliance with the mechanism which contains rules. The project bidding management system includes three major bodies of the state, the administrative departments of education at all levels, and the university. At the national level, we have Law of the People's Republic of China on Tenders and Bids and the Regulations under the Law of the People's Republic of China on Tenders and Bids, etc.; The regulations formulated by the administrative department of construction are applicable to the project bidding in universities; a series of project bidding management systems and control procedures are based on specific actual conditions in all universities.

The implementation of the higher level law and the higherlevel documents is based on the project bidding business management system made by the university in respect of its actual situation. The inadequate management method for university project bidding and unclear process will caused the relevant personnel of the bidding work deal with the problem based on their own preference or experience.

2) Lack of sound mechanism: The implementation of the system is under the corresponding operational mechanism. The systematic mechanism works in various bodies and system environments relying on a variety of methods. The university project bidding management system needs to integrate its procedures with methods to achieve a complete operational mechanism. At the same time, the serious implementation of the system also be realized with other related mechanisms, such as social management and supervision mechanisms, control and supervision mechanisms inside the universities. At present, the relevant technical documents such as bidding documents, bidding sum limits and lists for university project bidding are mostly entrusted by social consulting organizations with relevant qualifications to draw up, and bidding is carried out by agency, which further increases the risk of bidding work. In brief, the inadequate management mechanism of university project bidding, and the lack of supervision mechanism will cause the system fails to be implemented and be slowly executed or be unimplemented while appearing obedient; inadequate relevant mechanisms for effectively managing and supervising social consulting institutions are not perfect will cause uncontrollable clean governance risk.

3) Quality risk of bidding: The quality risk of project bidding in universities mainly means the lack of control in the bidding process caused by the poor business ability of the bidding staff or their loss of professional ethics. The reasons are: First, amid the "new normal" of economic development, the project bidding staff in university lags far behind that under the new situation in the knowledge, business capability and management level for the more complicated project bidding. Especially, the social consulting institutions fails to seize the key or supervision caused by lack of understanding of relevant national policies and poor risk awareness, so that there are occurrence of unqualified technical documents such as bidding documents and bill of quantities or loopholes deliberately, or the disciplinary violations of the social consulting agency manipulating the bidding process. Second, due to ignorance of confidentiality, relax in morality and ethics, lack of communication among all posts, poor awareness of integrity, and faded or declining professional ethics, the bidding staff actively disclose valuable information and more seriously to the joint social consulting organization, to manipulate the tendering process.

\section{PREVENTION AND CONTROL OF INTEGRITY RISKS IN UNIVERSITY PROJECT BIDDING}

The systematic control of clean governance risk in university project bidding involves the entire internal management of universities, especially project management, bidding procurement, auditing, discipline inspection and supervision, etc. It requires all personnel to control, from thinking to action, before, during and after the event.

\section{A. Strengthening the Clean Governance Mechanism Inside the Universities to Cope with Environmental Risks}

Materialist dialectics tells us that external factors are indispensable for the development of things, which sometimes plays a major role in the development of things; internal factors are the basis for the development of things, which determines the basic trends and directions of the development of things; No matter how important the external factor is, it must work with internal factors. Therefore, the fundamental solution to coping with environmental risks is to establish and improve the control mechanism of clean governance risks in university. 
Control of the clean governance risk includes three major bodies of the state, the administrative departments of education at all levels, and the university. Since the 18th CPC National Congress in 2012, the CPC Central Committee has stepped up strict governance over the Party into Four-Pronged Comprehensive Strategy, and has introduced a series of party rules and related supervision mechanisms, of which, inspection and supervision (a supervision system with Chinese characteristics) explores the full potential of socialist democratic supervision. The various clean governance systems drawn up by the education administrative department based on the characteristics of the education industry are applicable to all universities. According to the upper-level law or the higherlevel documents, all universities shall draft practical methods and rules, such as the "Implementation Measures for Control of the Clean Governance Risk in XX University" and the "Implementation Measures for the Clean Governance of XX University". For the important positions of the project bidding, the risk management level assessment shall be carried out, and party committee of the university shall sign the responsibility letter of integrity with the main-duty holders and personnel working in key positions. Formulate management and process of petitioning and reporting; establish an inspection and supervision mechanism inside the university, which focuses on solving problems and aims to building and implementation of control of clean governance risks, and internal control, and check the problem with a series of methods; For the clues found in the inspection, the party committee will determine the department to take responsibility and supervise the rectification of the problem. Aiming at clean governance risk warning and control, we will improve the internal clean governance supervision mechanism, enhance deterrents to corruption, strengthen the consciousness of incorruption, so that a culture of clean governance will be took shape in university.

\section{B. Improving the Management Mechanism of Project Bidding in University}

The universities draw up and develop project bidding management, such as "Project Bidding Management of XX University", including the project bidding management process and duty and responsibility, to clarify the project bidding procedures, methods and related responsibilities, in line with the relevant national laws and regulations and policy documents. The management of social consulting institutions shall be done in two aspects: First, strengthen the management of social consulting institutions, and set up management of the introduction, application, management and supervision of social consulting institutions, such as: "Management of Project Cost Consulting Organizations of XX University", "Management of Project Bidding Agency of XX University", etc.; regulate the methods and responsibilities of the project bidding staff to management and supervision of social consulting institutions. Second, sign a commission contract with the social consulting agency in line with the relevant national laws and regulations and the university's management regulations, of which the university will tighten scrutiny over the responsible party, service fee payment and post-evaluation to ensure its strict supervision.
The implementation of the system will be failed without supervision. The independent internal audit departments in most of the universities should take responsibility to implement auditing and supervision system to supervise the project bidding business of universities. Auditing the management level such as bidding procedures: for a largescale project bidding project, tracking audit mechanism should be took, and for a small-scale one, spot checks or special investigations should be took. Ensure that measures are put into place for the project bidding, which is common in the project bidding audit supervision so as to be part of the complete university project bidding management mechanism.

Supervisory responsibility emphasizes on treating symptoms, but investigating problems, working hard to against, improving the system and standardizing the process, is the solution to address root causes of the problems. What many departments and personnel related to the management of project bidding in universities shall establish and implement a sound internal control system is the long-term strategy for control of clean governance risks. We will sort out the clean governance risk points of the project bidding business and list the risks to analyze the causes of risks, which are at the management level, the relevant systems shall be improved, which are at business and technical level, the quality of work shall be improved by methods and means. For example, clean governance risk points in drawing up the tendering program: who shall call for bidding doesn't bid, or avoids bidding; clean governance risk points at the stage of issuing bid notice: failing to determine the winning bidder in accordance with the order of the winning bidder recommended by the bid evaluation committee, and the bidder does not issue the bid notice based on relevant regulations. For these issues at the management level, strengthen the bidder's responsibility in the management mechanism, and institutionalize major decisions. Project bidding management system and operation mechanism shall be drawn up or improved in accordance with the requirements of internal control regulations such as separation of zero-sum posts.

\section{Enhancing the Quality Control System and Improving the Professional Quality of Staff to Cope with the Quality Risks of Bidding}

Enhance the quality control system in respect of the list of clean governance risk points of project bidding, for example, some technical quality risk points in drafting bidding documents, including unreasonable conditions, the exclusion of potential bidders, the unreasonable bidding list and sun limit or the intentional loopholes. First, a clear stipulation of responsibility, improve the technical document review system, establish a tired quality control responsibility system, and list the quality responsibility; second, establish a special auditing system to control project bidding quality. For large project, its bidding documents and sum limits need to be reviewed by internal audit department before entering bidding process; for small-scale projects, make corrections promptly if there are any problems in its quality after spot-checked and audited.

The bidding is a legal and policy related work, which covers a large scope of knowledge that is updating rapidly, thus improving the profession and quality of staff is also 
effective to deal with the quality risk of bidding. Sort out common problems in project bidding, analyzing the causes of problems, proposing solutions to problems, forming written normative guidance, pragmatic manipulation norms, etc., for staff to learn. More training about new policies, new knowledge and new skills should be made for new bidding staff to enhance the knowledge structure, improve business capabilities. Establish a labor mobility mechanism with more positions to promote the staff to learn actively.

More education shall be made in ideology, secrecy and clean governance to improve the well-round development of the staff. By means of anti-corruption education film, confidential knowledge contests, expert lectures, etc., the sense of integrity and self-discipline will be grand into the staff so that they will be strictly abided by professional ethics.

\section{CONCLUSION}

As a microcosm of the research on the clean governance in universities, the research on control of clean governance risk in university project bidding has its own features. The paper aims to enrich the content of research on the construction of clean governance in universities.

\section{REFERENCES}

[1] Research Group of Shanghai Audit Society. Research on Audit Risk Management System of Audit Institutions [J]. Audit Research, 2018, 203(3): 40-46. (in Chinese)

[2] Zhang Guobing. Clean Government System in Colleges and Universities in the Perspective of control of clean governance risk Take the System of University Procurement Bidding as an Example[J].Journal of Beijing University of Technology (Social Science Edition),2013,13(2):76-81. (in Chinese)

[3] Xu Jie, Deng Yefen, He Ya. Thoughts on Implementation of the System of Strict Governance over The Party and Responsibility System in Universities[J].Ideological and Theoretical Education,2018(9):72-76. (in Chinese)

[4] Zhai Yongkai. Working Hard to Control the Risk of Clean Governance in Project Tender[J].Party Conduct and Party Discipline, 2013, (12): 80. (in Chinese)

[5] Xu Jie, Deng Yefen, He Ya. T Thoughts on Implementation of the System of Strict Governance over The Party and Responsibility System in Universities [J]. Ideological and Theoretical Education, 2018, (9): 7276. (in Chinese) 